\title{
A New Decision Method of Filling Ratio Based on Energy Matching of Surrounding Rock and Backfill
}

\author{
Yanlong Zhou $\mathbb{D}^{\mathrm{D}}$, Keping Zhou $\mathbb{D}$, and Yun Lin \\ School of Resources and Safety Engineering, Central South University, Changsha 410083, China \\ Correspondence should be addressed to Yun Lin; yunlin617@csu.edu.cn
}

Received 23 June 2020; Revised 13 July 2020; Accepted 23 July 2020; Published 5 August 2020

Academic Editor: Qian Yin

Copyright (C) 2020 Yanlong Zhou et al. This is an open access article distributed under the Creative Commons Attribution License, which permits unrestricted use, distribution, and reproduction in any medium, provided the original work is properly cited.

\begin{abstract}
In order to simplify the ratio decision process of cemented backfill in underground mines and achieve fine decision of filling ratio, the research on the energy matching between surrounding rock and cemented backfill in underground mines was conducted in this study. Based on the cubic function strength model of cemented backfill, the peak specific energy equation of backfill was improved by inversion analysis of the data of filling ratio experiment, and the functional relationship between the peak specific energy and the filling ratio was obtained by regression analysis. Then, based on the energy balance principle between the deformation energy released by the excavation of the underground rock mass and the peak specific energy of the cemented backfill, considering the physical and mechanical parameters of the surrounding rock of the goaf, including bulk density, elastic modulus, and burial depth, a ratio decision model of cemented backfill is established. The application results suggested that the calculation result of the model is reliable, and it can realize the rapid and accurate decision of the ratio of cement backfill in underground mines.
\end{abstract}

\section{Introduction}

Underground mineral resources provide indispensable materials for human use, but the excavation of underground mineral resources may cause a number of safety accidents, such as goaf instability caused by the excavation of underground ore bodies [1-6]. To ensure the stability of goafs in underground mines, underground rock mechanics [7-13] has been used to propose many measures, such as retaining isolated mine pillars and filling the goafs. Among them, filling the goafs is a more effective method [14-17] and has been gradually promoted in underground mines [18-21]. It is worth noting that the rock mass excavation and filling involved in underground mining is a typical fluid-solid coupling problem, and there are many influencing factors that make it difficult to obtain filling ratio of backfill quickly and accurately. In practical applications, the filling ratio of backfill is generally determined according to engineering experience, and the adopted values of the filling ratios are generally too large $[22,23]$. Although the goaf stability is guaranteed with high filling ratios, some other problems can arise, such as a waste of filling materials. Therefore, it is necessary to carry out research to determine a rapid and accurate decision-making method of the filling ratios of underground mines.

At present, most of the related research focuses on the mechanical properties of surrounding rock and backfill. For example, Fang and Fall [24] studied the shear mechanical properties of the interface between backfill and a rock mass. The characteristics of the mechanical interaction between backfill and a rock mass under the condition of creep behaviour were investigated by Qi and Fourie [25]. Hou et al. [26] analyzed the change law of mechanical properties during the process of the joint support of backfill and ore pillars. Liu et al. [27] explored the damage patterns of backfill and surrounding rock. Yan et al. [28] conducted a numerical analysis of the stress distribution characteristics of backfill.

The determination of the size of the filling body is one of the most critical issues in the mining process, but few related studies have been presented, and these earlier studies mainly concentrated on traditional methods, including ratio 
experiments and numerical simulation analyses [29-33]. For example, $\mathrm{Wu}$ et al. [34] chose the uniaxial compressive strength (UCS), slurry slump, and unit C binder consumption as response variables and then optimized the filling ratio of cemented backfill. Through the orthogonal experimental method, the best prescription of hemihydrate phosphogypsum was determined by Lan et al. [35]. Wen et al. [23] and Sun et al. [36] explored the optimal ratios of composite cementitious material based on fill tests and simulation analyses.

The traditional methods have the disadvantages of a long decision-making period, single results, and inflexibility. Aiming to establish a fast and accurate decision method for the filling ratio of cemented backfill, research on the energy balance between rock mass and backfill will be studied in this work.

\section{Establishment of the Energy Model of Backfill}

A goaf is formed in the excavation of an underground rock mass, and after the rock mass is excavated, its energy is released, which in turn causes the backfill to be gradually compressed and produce deformation energy. Considering the unconfined uniaxial compression characteristics, combined with the research results of relevant scholars [37], the peak specific energy of the unit volume backfill when it reaches the peak state can be expressed as

$$
V_{M}=\int_{0}^{\varepsilon_{M}} \sigma d \varepsilon
$$

where $V_{M}$ is the peak specific energy, $\mathrm{MJ} / \mathrm{m}^{3}, \sigma$ is the stress, $\mathrm{MPa}, \varepsilon$ is the strain, and $\varepsilon_{M}$ is the peak strain of the backfill.

By establishing the stress-strain relationship of the backfill, the peak specific energy of the backfill can be calculated. Many scholars have carried out research and analyses on model functions and established many damage functions that characterize the damage characteristics of backfill, but these functions have the following problems: (1) the form is generally very complicated, (2) the fitting effect is poor, and (3) the calculation is difficult. Considering that the strength curve of the backfill (shown in Figure 1) can be better described by a cubic function, some scholars have proposed cubic (shown in Equation (2)) stress-strain relationships of backfill. Thus, a cubic function will be utilized to analyze the energy of the backfill in this study.

$$
\sigma=a \varepsilon+b \varepsilon^{2}+c \varepsilon^{3}+d
$$

where $a, b, c$, and $d$ are constants, and $\varepsilon$ represents the strain of the backfill.

According to the characteristics of the stress-strain curve of the backfill, the following boundary conditions are considered [38].

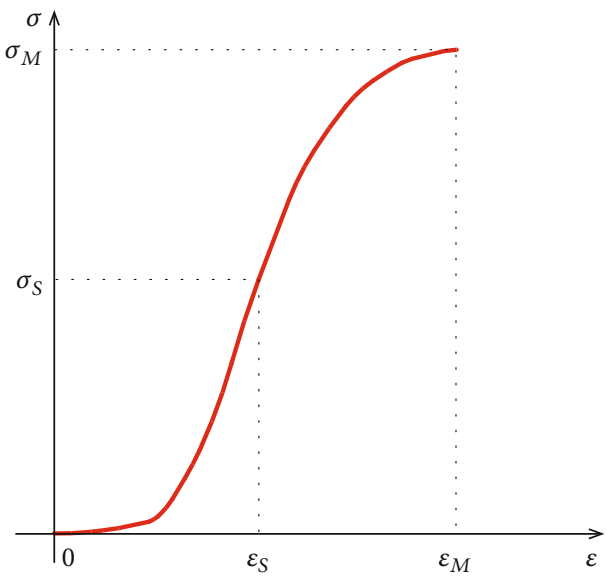

FIgURE 1: Schematic diagram of the stress-strain curve and inflection point of the backfill.

$$
\left\{\begin{array}{l}
\left.\sigma\right|_{\varepsilon=0}=0, \\
\left.\sigma\right|_{\varepsilon=\varepsilon_{M}}=\sigma_{M}, \\
\left.\frac{d \sigma}{d \varepsilon}\right|_{\mathcal{E}=\varepsilon_{M}}=0 \\
\left.\frac{d^{2} \sigma}{d \varepsilon^{2}}\right|_{\varepsilon=\varepsilon_{S}}=0
\end{array}\right.
$$

where $\varepsilon_{S}$ represents the strain at the inflection point of the curve.

Substituting Equation (2) into Equation (3), the following relationships can be obtained.

$$
\left\{\begin{array}{l}
a=\frac{\sigma_{M}\left(6 \varepsilon_{S}-3 \varepsilon_{M}\right)}{\varepsilon_{M}\left(3 \varepsilon_{S}-2 \varepsilon_{M}\right)}, \\
b=\frac{-3 \varepsilon_{S} \sigma_{M}}{\varepsilon_{M}^{2}\left(3 \varepsilon_{S}-2 \varepsilon_{M}\right)}, \\
c=\frac{\sigma_{M}}{\varepsilon_{M}^{2}\left(3 \varepsilon_{S}-2 \varepsilon_{M}\right)}, \\
d=0 .
\end{array}\right.
$$

Substituting Equation (4) into Equation (1), we have

$$
V_{M}=\int_{0}^{\varepsilon_{M}} \sigma d \varepsilon=\frac{\sigma_{M} \varepsilon_{M}\left(8 \varepsilon_{S}-5 \varepsilon_{M}\right)}{12 \varepsilon_{S}-8 \varepsilon_{M}} .
$$

\section{The Peak Specific Energy of Backfill}

3.1. Experimental Materials. The tailings used in this paper came from Baoshan Mine. The size distribution of the tailings is shown in Figure 2. The nonuniformity coefficient $C_{u}$ is $10.3\left(C_{u}>5\right)$, and the curvature coefficient $C_{c}$ is 1.27 $\left(1<C_{c}<3\right)$. Therefore, the tailings are coarse sand, and the gradation is good. The elemental components of the tailing are shown in Table 1 . It is known that $\mathrm{Si}, \mathrm{Al}$, and $\mathrm{Fe}$ contain less, which is helpful for strength performance. To reflect 


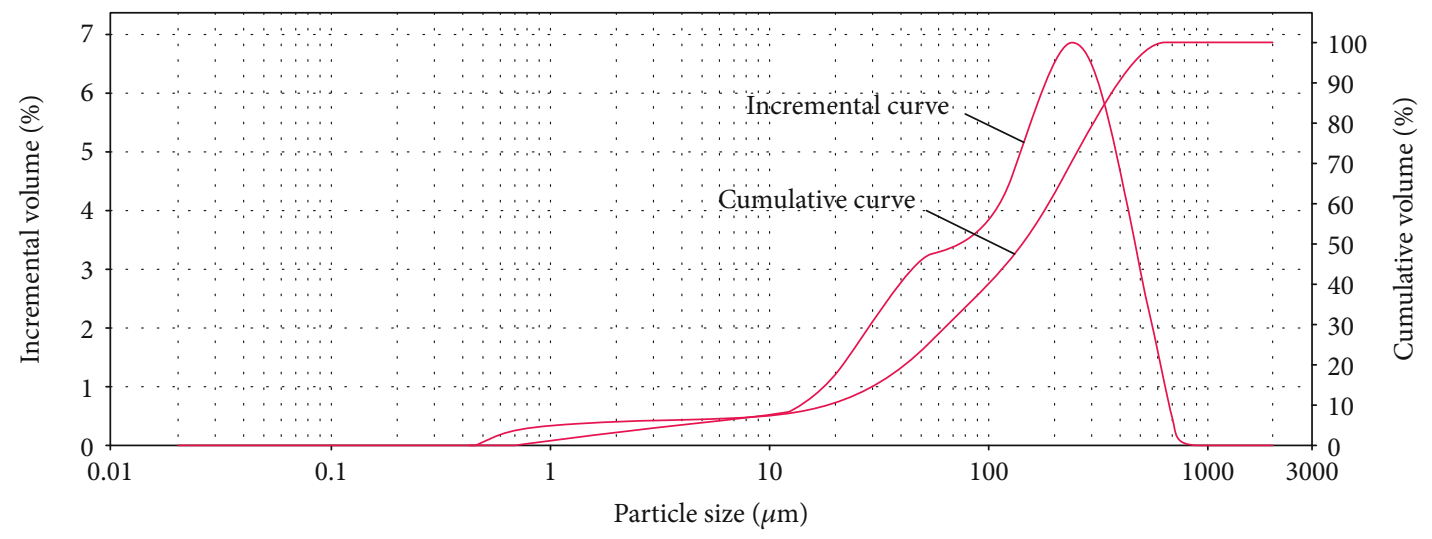

FIgURE 2: Size distribution curve of the tailings.

TABLE 1: Elemental components of the tailings.

\begin{tabular}{lcccccccccc}
\hline Element & $\mathrm{O}$ & $\mathrm{Na}$ & $\mathrm{Mg}$ & $\mathrm{Al}$ & $\mathrm{Si}$ & $\mathrm{S}$ & $\mathrm{Cl}$ & $\mathrm{K}$ & $\mathrm{Ca}$ & $\mathrm{Ti}$ \\
Content (\%) & 42.5 & 0.019 & 5.695 & 0.781 & 2.29 & 0.676 & 0.018 & 0.239 & 33.02 & 0.037 \\
Element & $\mathrm{Cr}$ & $\mathrm{Mn}$ & $\mathrm{Fe}$ & $\mathrm{Cu}$ & $\mathrm{Zn}$ & $\mathrm{As}$ & $\mathrm{Rb}$ & $\mathrm{Sr}$ & $\mathrm{Zr}$ & $\mathrm{Pb}$ \\
Content (\%) & 0.006 & 0.468 & 1.316 & 0.0141 & 0.104 & 0.13 & 0.002 & 0.0252 & 0.0013 & 0.179 \\
\hline
\end{tabular}

with the actual situation on site and the elemental components of the tailing, ordinary 425 Portland cement was used as the cementing material and was mixed with tap water.

3.2. Experiment of Backfilling Ratio. The tailings were dried at $105^{\circ} \mathrm{C}$ for 12 hours and then sieved. As required by the standards of ISRM suggested, a high-quality standard $\varphi 50 \mathrm{~mm} \times \mathrm{H} 100 \mathrm{~mm}$ cylindrical mould was used to prepare the samples [39]. The cement-tailings ratio (designated $R$ ) of the backfill were set to $1: 4,1: 6,1: 8,1: 10$, $1: 12,1: 15$, and $1: 20$ according to the actual mine conditions and engineering experience, and the mass concentration was $80 \%$ (shown in Figure 3). Then, the samples were placed in the standard curing box. After being cured for 28 days under standard curing conditions (temperature of $20^{\circ} \mathrm{C}$ and humidity of $95 \%$ ), unconfined uniaxial compressive strength test was carried out (results shown in Figure 4).

3.3. Parameter Determination. It can be seen from Equation (5) that the determination of the inflection point is the key in the calculation of the peak specific energy of the cemented backfill. Considering the characteristics of the stress-strain curves of the cemented backfill, the coefficient $k$ was introduced. If $0<k<1$ and substituting $k$ into Equation (5), we have

$$
V_{M}=\int_{0}^{\varepsilon_{M}} \sigma d \varepsilon=\frac{\sigma_{M} \varepsilon_{M}\left(8 \varepsilon_{S}-5 \varepsilon_{M}\right)}{12 \varepsilon_{S}-8 \varepsilon_{M}}=\frac{\sigma_{M} \varepsilon_{M}(8 k-5)}{12 k-8} .
$$

According to Equation (6), the coefficient $k$ can be expressed as

$$
k=\frac{8 V_{M}-5 \sigma_{M} \varepsilon_{M}}{12 V_{M}-8 \sigma_{M} \varepsilon_{M}}
$$

According to Equation (1), the peak specific energy of the cemented backfill could be calculated based on the stress and strain data of the cemented backfill obtained through the experiments. Then, according to Equation (7), the coefficient $k$ of the cemented backfill under different filling ratios can be obtained $[40,41]$. The experimental and statistical results are shown in Table 2 , and the representative stress-strain curve (filling ratio is $1: 4$ ) is shown in Figure 5.

The test results show that the materials have a better bonding effect and higher strength due to a more suitable gelling material and a better tailings gradation. Furthermore, the curve characteristics before the peak closely match the characteristics of the cubic function curve. There was an operation error during the data acquisition from the test of a filling ratio of $1: 12$; thus, these data are omitted in subsequent calculations.

As shown in Table 1, the $k$ values under different ratios is relatively close and fluctuate at approximately 0.55 . Considering the simplicity of the calculation equation, the $k$ value is 0.55 in this study. Taking the value of $k$ into Equation (6), we have

$V_{M}=\int_{0}^{\varepsilon_{M}} \sigma d \varepsilon=\frac{\sigma_{M} \varepsilon_{M}\left(8 \varepsilon_{S}-5 \varepsilon_{M}\right)}{12 \varepsilon_{S}-8 \varepsilon_{M}}=\frac{\sigma_{M} \varepsilon_{M}(8 k-5)}{12 k-8} \approx \frac{\sigma_{M} \varepsilon_{M}}{2.4}$.

Compared with the calculation results of the peak specific energy of cemented backfill based on the test data (shown in Figure 6), it can be found that the calculation results based on Equation (8) are accurate and reliable. Thus, it can be concluded that it is feasible to fix the coefficient $k$ to 0.55 in this study.

According to the peak specific energy of cemented backfill under different cement-tailings ratios $R$ in Table 1 , the 


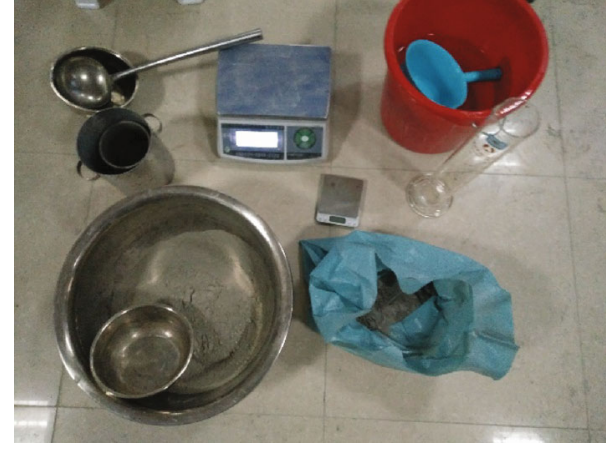

Figure 3: Filling ratio experiment.

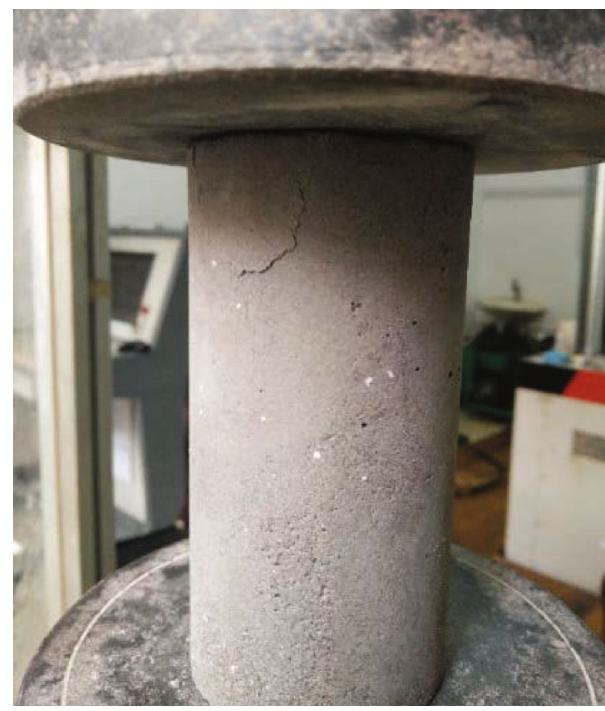

Figure 4: Uniaxial compressive strength test.

relationship between these factors was analyzed [42, 43]. Figure 7 shows that the peak specific energy of the cemented backfill has an exponential relationship with the filling ratio, and the correlation coefficient $R^{2}$ can reach $0.995[44,45]$. The relationship can be written as

$$
V_{M}=\frac{\sigma_{M} \varepsilon_{M}}{2.4}=0.00166+0.11656 e^{-1 / 3.06302 R} .
$$

\section{Analysis of Energy Balance between Surrounding Rock and Cemented Backfill}

4.1. Specific Energy of Surrounding Rock. Under the original stress environment, the original rock is compressed and stores deformation energy [37]. After excavation, the energy released per unit of rock mass in the goaf is

$$
V_{R}=\int_{\varepsilon_{0}}^{0} \sigma d \varepsilon=-\frac{\sigma_{0}^{2}}{2 E_{0}},
$$

where $V_{R}$ represents the specific energy of the surrounding rock, $\mathrm{MJ} / \mathrm{m}^{3}, \sigma_{0}$ is the rock stress, $\mathrm{MPa}$, and $E_{0}$ is the elastic modulus of the surrounding rock, GPa.
Regardless of the tectonic stress, the specific energy of the surrounding rock in the goaf can be expressed as

$$
V_{R}=\int_{\varepsilon_{0}}^{0} \sigma d \varepsilon=-\frac{\sigma_{0}^{2}}{2 E_{0}}=-\frac{\gamma^{2} H^{2}}{2 E_{0}},
$$

where $\gamma$ is the bulk density of the overlying strata, $\mathrm{kN} / \mathrm{m}^{3}$, and $H$ represents the thickness of the overlying strata, $\mathrm{m}$.

4.2. Analysis of Energy Balance. Excavation of the stope causes the energy of the surrounding rock to be released. After filling into the goaf, the cemented backfill is compressed to produce deformation energy. Considering the stability of the goaf, the peak deformation energy (peak specific energy) of the cemented backfill should be able to withstand the release of energy from the surrounding rocks. Introducing the balance coefficient $(K>1)$ [46-48], the energy relationship between the cemented backfill and the surrounding rock is

$$
V_{M}=-K V_{R}
$$

Substituting Equation (9) into Equation (12), we have

$$
0.00166+0.11656 e^{-1 / 3.06302 R}=K \frac{\gamma^{2} H^{2}}{2 E_{0}} .
$$

Then, the filling ratio $R$ can be written as

$$
\frac{1}{R}=-3.06302 \ln \frac{K \gamma^{2} H^{2}-0.00332 E_{0}}{0.23312 E_{0}} .
$$

\section{Application Analysis}

The surrounding rock of the Baoshan Mine is sandstone. Laboratory experiments have indicated that the physical and mechanical properties of the surrounding rock at different burial depths remain approximately unchanged. The bulk density of the surrounding rock is $22 \mathrm{kN} / \mathrm{m}^{3}$, and the elastic modulus is $3.7 \mathrm{GPa}$. At present, the burial depths of the main production level are $582 \mathrm{~m}, 622 \mathrm{~m}$, and $702 \mathrm{~m}$. The filling ratio of the backfill is not determined according to the amount of energy released by the surrounding rock at different burial depths, and the current filling ratio is assumed to be $1: 6-1: 8$, which causes excessive consumption of materials. Therefore, it is necessary to adopt a more rapid and effective method to determine reasonable filling ratio of cemented backfill at different burial depths. According to the characteristics of the physical and mechanical parameters of the surrounding rocks, combined with the actual conditions of the mine, the balance coefficient $K$ is set to 1.5 , and then, the filling ratios of the backfill at different burial depths are calculated based on Equation (14). The results are shown in Table 3, where $R$ ' represents the recommended filling ratio based on the actual application.

According to the calculation results, the filling ratios of the cemented backfill with the levels of $582 \mathrm{~m}, 622 \mathrm{~m}$, and $702 \mathrm{~m}$ were selected as $1: 13,1: 12$, and $1: 11$, respectively. 
TABLE 2: The experimental results and the value of $k$ under different ratios of cemented backfill.

\begin{tabular}{|c|c|c|c|c|c|c|}
\hline Number & Ratio parameter & Elastic modulus (MPa) & Stress $(\mathrm{MPa})$ & Strain $(\%)$ & Peak specific energy $\left(\mathrm{MJ} / \mathrm{m}^{3}\right)$ & $k$ \\
\hline 1 & $1: 4$ & 1140.24 & 8.21 & 0.9624 & 0.03449 & 0.546 \\
\hline 2 & $1: 6$ & 769.2 & 5.18 & 0.8986 & 0.01851 & 0.563 \\
\hline 3 & $1: 8$ & 532.33 & 2.66 & 0.8039 & 0.00846 & 0.564 \\
\hline 4 & $1: 10$ & 371.13 & 2.02 & 0.7212 & 0.00606 & 0.556 \\
\hline 5 & $1: 12$ & 328.06 & 1.35 & 0.7066 & - & 0.597 \\
\hline 6 & $1: 15$ & 282.74 & 0.99 & 0.7028 & 0.00350 & 0.497 \\
\hline 7 & $1: 20$ & 169.21 & 0.67 & 0.6609 & 0.00207 & 0.527 \\
\hline
\end{tabular}

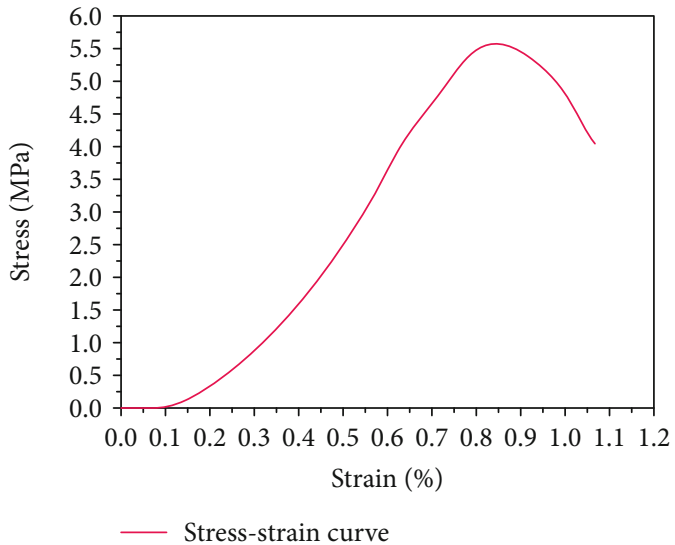

FIgURE 5: Representative stress-strain curve.

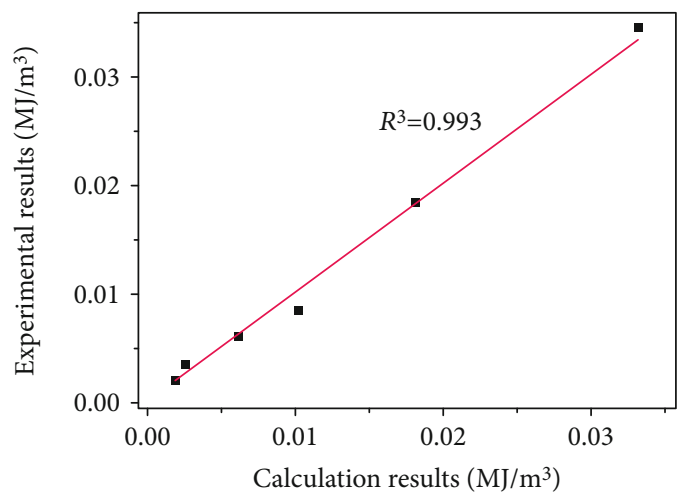

Figure 6: Correlation between calculation results and experimental results.

Then, the filling ratios were applied to the actual engineering of this time. In the field application, it was found that the goafs have remained stable since filling, which indicates that the filling ratios of the cemented backfill determined by this method are reasonable and can be applied to engineering practice. It also further suggests that it is feasible to determine the filling ratios of backfill based on the method proposed in this study. At the same time, the filling ratio determined by the conventional engineering experience is relatively high. However, when the determination of the filling ratio based on the method in this study was applied, excessive consumption of materials is thus avoided to a certain extent.

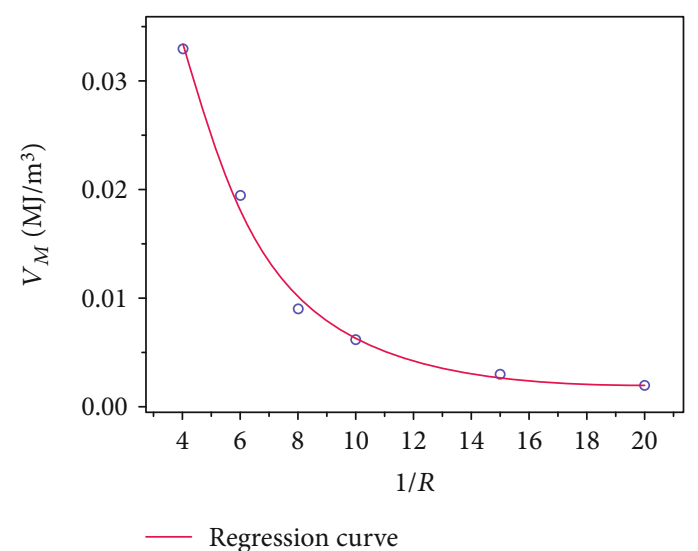

Figure 7: The relationship between the peak specific energy of the backfill and the filling ratio.

TABLE 3: Results of filling ratios of the backfill with different burial depths.

\begin{tabular}{lccc}
\hline Depth $(\mathrm{m})$ & $-K V_{R}$ & $R$ & $R$ \\
\hline 582 & 0.00332 & $1: 13.01688$ & $1: 13$ \\
622 & 0.00380 & $1: 12.25097$ & $1: 12$ \\
702 & 0.00483 & $1: 11.03655$ & $1: 11$ \\
\hline
\end{tabular}

\section{Discussion}

Although the proposed method was only tested on one mine, it is expected that this method can also be applied to other mines because the principle of energy balance between surrounding rock and backfill is universal. Moreover, it should be noted that because different mines have different geological characteristics, the value of the coefficient $k$ should be determined according to experimental results of surrounding rock and backfill when this method is applied to other mines.

In addition, to simplify the calculation, the value of $k$ was fixed at 0.55 . Although the application results suggest this simplification is feasible, the research of different $k$ values is still necessary and will be carried out in the future.

\section{Conclusions}

The purpose of this research was to determine a new methodology for assessing the filling ratios of backfill in mines, and 
the following conclusions were drawn based on the results obtained in this study:

(1) The coefficient $k$ was introduced to characterize the position of the inflection point in the stress-strain curve, and the value of $k$ was fixed at 0.55 through experimental data. The verification results showed that this simplification is reasonable and feasible

(2) The peak energy equation of cemented backfill was improved, and it was found that the peak specific energy of the cemented backfill has a linear relationship with the peak stress and strain of the backfill

(3) Based on the energy balance principle of the surrounding rock and backfill, considering the bulk density, elastic modulus, and burial depth of the surrounding rock, a relational function model of the filling ratio was established. The application results indicated that the model established in this study is simple and accurate and can be used to determine the backfill ratios of underground mines. Moreover, it is expected that this method can also be applied to other mines as described in the section of discussion

\section{Data Availability}

Most of the data generated or analysed during this study are included in this manuscript, and all of the data are available from the corresponding author on reasonable request.

\section{Conflicts of Interest}

The authors declare that they have no conflicts of interest.

\section{Acknowledgments}

The research presented in this paper was jointly supported by the National Natural Science Foundation of China (Grant no. 51774323).

\section{References}

[1] E. Yilmaz, "Stope depth effect on field behaviour and performance of cemented paste backfills," International Journal of Mining Reclamation and Environment, vol. 32, no. 4, pp. 273-296, 2018.

[2] C. Zhu, M. C. He, M. Karakus, X. B. Cui, and Z. G. Tao, "Investigating toppling failure mechanism of anti-dip layered slope due to excavation by physical modelling," Rock Mechanics and Rock Engineering, vol. 2020, pp. 1-20, 2020.

[3] D. Ren, D. Zhou, D. Liu, F. Dong, S. Ma, and H. Huang, "Formation mechanism of the Upper Triassic Yanchang Formation tight sandstone reservoir in Ordos Basin-Take Chang 6 reservoir in Jiyuan oil field as an example," Journal of Petroleum Science and Engineering, vol. 178, pp. 497-505, 2019.

[4] P. Shan and X. Lai, "An associated evaluation methodology of initial stress level of coal-rock masses in steeply inclined coal seams, Urumchi coal field, China," Engineering Computations, vol. 37, no. 6, pp. 2177-2192, 2020.
[5] N. Zhang, W. Liu, Y. Zhang, P. Shan, and X. Shi, "Microscopic pore structure of surrounding rock for underground strategic petroleum reserve (SPR) caverns in bedded rock salt," Energies, vol. 13, no. 7, article 1565, 2020.

[6] S. Bacha, Z. Mu, A. Javed, and S. Al Faisal, "A review of rock burst's experimental progress, warning, prediction, control and damage potential measures," Journal of Mining and Environment, vol. 11, no. 1, pp. 31-48, 2020.

[7] Q. Yin, R. C. Liu, H. W. Jing, H. J. Su, L. Y. Yu, and L. X. He, "Experimental study of nonlinear flow behaviors through fractured rock samples after High-Temperature exposure," Rock Mechanics and Rock Engineering, vol. 52, no. 9, pp. 29632983, 2019.

[8] Q. Yin, G. W. Ma, H. W. Jing et al., "Hydraulic properties of 3D rough-walled fractures during shearing: an experimental study," Journal of Hydrology, vol. 555, pp. 169-184, 2017.

[9] Q. Yin, H. W. Jing, G. W. Ma, H. J. Su, and R. C. Liu, "Investigating the roles of included angle and loading condition on the critical hydraulic gradient of real rock fracture networks," Rock Mechanics and Rock Engineering, vol. 51, no. 10, pp. 3167-3177, 2018.

[10] G. Feng, Y. Kang, X. Wang, Y. Hu, and X. Li, "Investigation on the failure characteristics and fracture classification of shale under brazilian test conditions," Rock Mechanics and Rock Engineering, vol. 53, no. 7, pp. 3325-3340, 2020.

[11] G. Feng, X. C. Wang, M. Wang, and Y. Kang, "Experimental investigation of thermal cycling effect on fracture characteristics of granite in a geothermal-energy reservoir," Engineering Fracture Mechanics, vol. 235, article 107180, 2020.

[12] D. Liu, Z. Gu, R. Liang et al., "Impacts of pore-throat system on fractal characterization of tight sandstones," Geofluids, vol. 2020, Article ID 4941501, 17 pages, 2020.

[13] H. Huang, T. Babadagli, X. Chen, H. Z. Li, and Y. M. Zhang, "Performance comparison of novel chemical agents for mitigating water-blocking problem in tight gas sandstones," $S P E$ Reservoir Evaluation \& Engineering, 2020.

[14] J. Wang, D. P. Qiao, R. S. Han, G. T. Li, and J. C. Xie, "Strength model of cemented backfill in subsequent filling at the stage of open stope and its application," Rock and Soil Mechanics, vol. 40, no. 3, pp. 1105-1112, 2019.

[15] B. A. Lingga, D. B. Apel, M. Sepehri, and Y. Y. Pu, "Assessment of digital image correlation method in determining large scale cemented rockfill strains," International Journal of Mining Science and Technology, vol. 29, no. 5, pp. 771776, 2019.

[16] Z. Z. Zhang, W. J. Wang, S. Q. Li, and X. Y. Yu, “Analysis on rockbolt support interaction with roof dilatancy above roadside backfill area in gob-side entry retaining," Geotechnical and Geological Engineering, vol. 36, no. 4, pp. 2577-2591, 2018.

[17] Y. Zhang, S. G. Cao, N. Zhang, and C. Z. Zhao, "The application of short-wall block backfill mining to preserve surface water resources in northwest China," Journal of Cleaner Production, vol. 261, article 121232, 2020.

[18] S. J. Chen, D. W. Yin, N. Jiang, F. Wang, and Z. H. Zhao, "Mechanical properties of oil shale-coal composite samples," International Journal of Rock Mechanics and Mining Sciences, vol. 123, article 104120, 2019.

[19] S. Zhu, Q. S. Chen, Q. L. Zhang, and D. M. Zhang, "Recycling lead-zinc tailings for cemented paste backfill and stabilisation of excessive metal," Minerals, vol. 9, no. 11, article 710, 2019. 
[20] N. Jiang, C. Wang, H. Pan, D. Yin, and J. Ma, "Modeling study on the influence of the strip filling mining sequence on mining-induced failure," Energy Science \& Engineering, vol. 8, no. 6, pp. 2239-2255, 2020.

[21] C. Wang, B. Shen, J. Chen et al., "Compression characteristics of filling gangue and simulation of mining with gangue backfilling: an experimental investigation," Geomechanics and Engineering, vol. 20, no. 6, pp. 485-495, 2020.

[22] C. C. Qi, A. Fourie, Q. S. Chen, and Q. L. Zhang, "A strength prediction model using artificial intelligence for recycling waste tailings as cemented paste backfill," Journal of Cleaner Production, vol. 183, pp. 566-578, 2018.

[23] Z. J. Wen, Q. Gao, Y. D. Wang, and X. B. Yang, "Development of composite cementitious material and optimization of slurry proportion based on fuzzy comprehensive evaluation," The Chinese Journal of Nonferrous Metals, vol. 30, no. 3, pp. 698707, 2020.

[24] K. Fang and M. Fall, "Shear behavior of the interface between rock and cemented backfill: effect of curing stress, drainage condition and backfilling rate," Rock Mechanics and Rock Engineering, vol. 53, no. 1, pp. 325-336, 2020.

[25] C. C. Qi and A. Fourie, "Numerical investigation of the stress distribution in backfilled stopes considering creep behaviour of rock mass," Rock Mechanics and Rock Engineering, vol. 52, no. 9, pp. 3353-3371, 2019.

[26] C. Hou, W. C. Zhu, B. X. Yan, K. Guan, and L. L. Niu, “Analytical and experimental study of cemented backfill and pillar interactions," International Journal of Geomechanics, vol. 19, no. 8, article 04019080, 2019.

[27] Z. X. Liu, M. Lan, S. Y. Xiao, and H. Q. Guo, "Damage failure of cemented backfill and its reasonable match with rock mass," Transactions of Nonferrous Metals Society of China, vol. 25, no. 3, pp. 954-959, 2015.

[28] B. X. Yan, W. C. Zhu, C. Hou, and H. W. Jia, “A comparative study on the stress distribution in mine backfill through theoretical and numerical analysis," Journal of Northeastern University (Natural Science), vol. 40, no. 12, pp. 1773-1778, 2019.

[29] J. Wang, J. X. Fu, W. D. Song, Y. F. Zhang, and Y. Wang, "Particle flow simulation of mechanical properties and microcrack evolution characteristics of rock-backfill combined model," Journal of China University of Mining \& Technology, vol. 49, no. 3, pp. 453-462, 2020.

[30] H. Suhara, Y. Sawa, M. Nishimura et al., "Efficacy of a new coating material, PMEA, for cardiopulmonary bypass circuits in a porcine model," Annals of Thoracic Surgery, vol. 71, no. 5, pp. 1603-1608, 2001.

[31] C. Hou, W. Zhu, B. Yan, K. Guan, and J. du, "Influence of binder content on temperature and internal strain evolution of early age cemented tailings backfill," Construction and Building Materials, vol. 189, pp. 585-593, 2018.

[32] Y. Wang, C. H. Li, Z. Q. Hou, X. F. Yi, and X. M. Wei, "In vivo $\mathrm{X}$-ray computed tomography investigations of crack damage evolution of Cemented Waste Rock Backfills (CWRB) under uniaxial deformation," Minerals, vol. 8, no. 11, article 539, 2018.

[33] M. Li, J. X. Zhang, P. Huang, and R. Gao, "Mass ratio design based on compaction properties of backfill materials," Journal of Central South University, vol. 23, no. 10, pp. 2669-2675, 2016.

[34] H. Wu, G. Z. Zhao, Y. Chen, and H. Y. Zhang, "Optimization of mix proportioning of mine filling materials using RSM-DF experiments design method," Journal of Basic Science and Engineering, vol. 27, no. 2, pp. 453-461, 2019.

[35] W. T. Lan, A. X. Wu, Y. M. Wang, and J. Q. Li, "Optimization of filling ratio of hemihydrate phosphogypsum based on orthogonal test," The Chinese Journal of Nonferrous Metals, vol. 29, no. 5, pp. 1083-1091, 2019.

[36] G. J. Sun, P. Wang, T. Feng, W. J. Yu, and J. H. Liu, "Strata movement characteristics of the deep well gangue filling on the fully mechanized mining face," Journal of Mining \& Safety Engineering, vol. 37, no. 3, pp. 562-570, 2020.

[37] K. Du, L. I. Xi-bing, D.-y. Li, and L. Weng, "Failure properties of rocks in true triaxial unloading compressive test," Transactions of Nonferrous Metals Society of China, vol. 25, no. 2, pp. 571-581, 2015.

[38] Y. X. Ke, X. M. Wang, Q. L. Zhang, and E. Y. Liu, "Strength determination of crude tailings backfill in deep mine based on non-linear constitutive model," Journal of Northeastern University (Natural Science), vol. 38, no. 2, pp. 280-283, 2017.

[39] W. Xu, M. Han, and P. Li, "Influence of freeze-thaw cycles on mechanical responses of cemented paste tailings in surface storage," International Journal of Mining Reclamation and Environment, vol. 34, no. 5, pp. 326-342, 2020.

[40] T. Alkhamaiseh, L. Mejus, I. Yusoff, and R. Yaccup, "Relationships between geophysical and geotechnical parameters focusing on a site specific results of a landslide risk area," Amazonia Investiga, vol. 7, no. 15, pp. 386-398, 2018.

[41] K. Fang and M. Fall, "Effects of curing temperature on shear behaviour of cemented paste backfill- rock interface," International Journal of Rock Mechanics and Mining Sciences, vol. 112, pp. 184-192, 2018.

[42] S. Zamiran and A. Osouli, "Seismic motion response and fragility analyses of cantilever retaining walls with cohesive backfill," Soils and Foundations, vol. 58, no. 2, pp. 412-426, 2018.

[43] H. Basarir, H. Bin, and A. Fourie, "An adaptive neuro fuzzy inference system to model the uniaxial compressive strength of cemented hydraulic backfill," Mining of Mineral Deposits, vol. 12, no. 2, pp. 1-12, 2018.

[44] E. Tavasoli, G. Asadollahfardi, A. Khodadadi Darban, and M. Asadi, "Simulation of cyanide oxidation using calcium and sodium hypochlorite in the Moteh Gold Mine Tailing Dam, Iran," Desalination and Water Treatment, vol. 145, pp. 273-279, 2019.

[45] L. Peng, J. J. Mei, N. Wang et al., "Quantitative inversion of water quality parameters in industrial and mining cities from hyperspectral remote sensing," Spectroscopy and Spectral Analysis, vol. 39, no. 9, pp. 2922-2928, 2019.

[46] N. H. Alaee, A. Mozafari, M. Mirzaee, A. Faghihi, and K. Tolouei, "Fuzzy evaluation method for the identification of subsidence susceptibility in an underground mine (case study in Tabas coal mine of Iran)," Natural Hazards, vol. 99, no. 2, pp. 797-806, 2019.

[47] B. X. Yan, W. C. Zhu, and C. Hou, "Theoretical analysis of maximum exposure height of the backfill when mining underground adjacent stope," Hazard Control in Tunnelling and Underground Engineering, vol. 1, no. 2, pp. 100-106, 2019.

[48] G. Feng, Z. Li, Y. Guo et al., "175 Mix ratio optimization of cemented Coal Gangue Backfill (CGB) based on response surface method," Journal of Residuals Science \& Technology, vol. 13, no. 3, pp. 175-184, 2016. 